\title{
CHARACTERIZATION OF FOUR TYPICAL CALABRIAN CURED MEAT PRODUCTS: SPICY SAUSAGE, SOPPRESSATA, 'NDUJA AND CAPOCOLLO
}

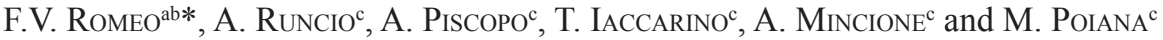 \\ ${ }^{a}$ Consiglio per la Ricerca e la Sperimentazione in Agricoltura - Olive growing and olive oil industry \\ Research Centre (CRA-OLI), C.da Li Rocchi, 87036 Rende (CS). Italy \\ ${ }^{\mathrm{b}}$ Consiglio per la Ricerca e la Sperimentazione in Agricoltura - Research Centre for Citriculture \\ and Mediterranean Crops (CRA-ACM), Corso Savoia, 190 - 95024 Acireale (CT). Italy \\ 'BIOMAA - Department of Biotechnologies for Agricultural Food and Environmental Monitoring, \\ Mediterranean University of Reggio Calabria, C. da Melissari, 89124 (RC). Italy
}

(Received: 10 September 2012; accepted: 14 January 2013)

Typical Calabrian cured meat products, produced with meat of local and commercial pig breeds were evaluated and characterized for their quality and homogeneity. Sensory, microbiological and physicochemical analyses were carried out at the end of cured meat products ripening. A wide statistical variability was observed in these commercial products due to both company and different productions. The mineral composition was similar to that observed by other authors in similar cured meat products; the statistical analysis revealed only a difference among the samples for magnesium $(\mathrm{P}<0.01)$ and for calcium $(\mathrm{P}<0.05)$ contents. According to the performed sensory analysis, the meat products were acceptable with some differences due to both production and company variables. About microbial populations, the most abundant were lactic acid bacteria and total aerobic bacteria, while enterobacteria were less represented.

Keywords: cured meat, microbial quality, mineral composition, sensorial quality, typical food

Typical food is defined as a product made in a non-industrial environment, traditional or unique, characterized by small-scale batch production with a limited degree of mechanization (KuPIEC \& Revell, 1998). A typical food is specially linked with a given territory. In a changing context of consumption culture, the interest of consumers with respect to the socalled "typical" foods is increased, in particular in Italy (IACCARINO et al., 2006). Some different Italian salami are registered as a protected designation of origin (PDO) or geographical indication (PGI) according to European Council Regulation (EC, 2006), and, among these, four typical cured meat products of Calabria region ("soppressata, capocollo, salsiccia and pancetta", EC, 1998) received the PDO in the last ten years.

Pork is the main used meat and fungal starter cultures are sometimes used on the external surface (TALON et al., 2004). Usually $2-4 \% \mathrm{NaCl}$ is added, assuring the microbiological stability (OCKERMAN \& BASU, 2007) and enhancing flavour, texture, and shelf-life of meat products (RuUsunen \& Puolanne, 2005). In large-scale processes devised for the production of rapid ripened sausages, nitrite salts are used as the only curing agents and mixed starter cultures containing both lactic acid bacteria and Micrococcaceae strains are usually inoculated (SANZ et al., 1997).

Among the excellent Calabrian gastronomic products, cured meat products are very representative for the role of the pork as primary source of survival. The pigs are nourished

\footnotetext{
* To whom correspondence should be addressed.

Phone: +39 095 7653128; fax: +39 095 7653113; e-mail: floravaleria.romeo@entecra.it
} 
with local foods and they are subjected to better life conditions than ones bred in intensive livestock farming.

The spicy sausage (salsiccia) has cylindrical shape with varying length and thickness and can be intertwined. Its appearance of red colour and the hot flavouring are due to the presence of red pepper in its preparation. The used ingredients are: about $80 \%$ boneless pork lean meat (shoulder and rib), about 20\% lard, and spices as ground black pepper, hot and red pepper. The ripening lasts about 2 months.

The soppressata has a lightly flat cylindrical shape. Its appearance is compact after cutting, it is soft and of red colour. The lean portion is composed of the cuts of ham and shoulder, the fat $(15 \%$ of the total) derives from the loin beside the neck. Salt, black and red pepper, and often also chili sauce are added. The ripening lasts for 3-6 months.

The capocollo is composed of the upper part of the pork loin that is boned and drysalted, with the adding of the covering fat to obtain a softer texture during the ripening. Also, red and black pepper could be present in its preparation. It is not a salami because it is not produced with minced meat. Generally it is also smoked to gain the typical flavour and preservation for several months.

The "nduja salami originates from the Calabria region as "poor food" for the need of the farmers to use the pork meat remaining after the fine cuts were destined to the landholders. 'Nduja is a unique salami having a creamy texture, so it is spread and very versatile in cooking recipes. In this preparation, the fatty parts of pork, lard, fat and underbelly are mixed with red pepper, salt and natural flavourings. The rate pork/red pepper varies from 2:1 to 3:1. The pepper is obtained from cultivated plants in the Mount Poro (Calabria, Italy) belonging to hot or sweet cultivars. An eventual smoking is carried out with particularly aromatic wood. The ripening lasts for about 1-2 months. No microbial starters are added to these meat preparations.

The aim of this work was to evaluate chemical, microbiological and sensory characteristics of four typical Calabrian cured meat products, produced from Italian pork meat, in order to better characterize these ripened products.

\section{Materials and methods}

\subsection{Cured meat sampling}

Ten cured pork meat producing companies were selected in four provinces of the Calabria region: Cosenza, Reggio Calabria, Vibo Valentia and Catanzaro (Italy). The selection was applied for the geographic position and for the production rate. The attention was turned on little manufactures working continuously during the year, and dairy farms with semiindustrial production. The monitored companies own an amount of bred heads ranging from 250 to 2500 and supply principally the local market. Among these, two companies sell their products also to the national market.

The cured meat products were prepared using the most valuable cuts from pig breeds Large white, Landrance, Duroc, Nero Calabrese and several hybrids. All the four Calabrian products were stuffed in natural casings from pig intestine and were stored in traditional ripening rooms where the temperature ranged from 10 to $12{ }^{\circ} \mathrm{C}$ for 'Nduja and from 14 to $18{ }^{\circ} \mathrm{C}$ for the other products, while the R.H. ranged from 70 to $85 \%$. Four pork meat preparations were sampled three times in each farm. The analysed products were spicy 
sausage (SAU), soppressata (SOP), "nduja (ND) and capocollo (CAP). The size of the sampled products was 500-600 g (SAU), 400-500 g (SOP), $500 \mathrm{~g}$ (ND) and 2-3 kg (CAP).

\subsection{Chemical analyses}

The $\mathrm{pH}$ value was measured by a $\mathrm{pH}$ meter (Crison Basic 20) equipped with an electrode for solid surfaces (Crison 5232).

The moisture, ash, and chlorides analyses were carried out according to A.O.A.C. methods a, b and c, respectively (A.O.A.C., 2000).

The water activity of homogenized samples was measured by an Aqua lab (3TE, Decagon devices Inc., Washington) apparatus, which uses the chilled-mirror dewpoint technique.

The protein content was obtained according to Kjeldahl method d (A.O.A.C., 2000) through a DK6 Heating Digester and UDK 132 Semiautomatic distillation unit (Velp Scientifica).

The fat content was determined with Soxhlet method through the extraction (mod. BE 6, Sical) with petroleum ether after acid hydrolysis.

Calcium, magnesium, potassium, sodium, iron, zinc and manganese contents were determined by atomic absorption spectrophotometer (Perkin Elmer AAnalyst 100), measuring the amount of light absorbed at a specific wavelength by using a hollow cathode lamp as the primary light source, a monochromator and a detector. A mixture of acetylene:air was used for flame alimentation. The software AA WinLabTM was employed.

\subsection{Microbiological analyses}

After the surface peeling, $10 \mathrm{~g}$ of the single homogenized sample were transferred into sterile stomaching bags (BagFilter P/10, $400 \mathrm{ml}$, Interscience) combined with $90 \mathrm{ml}$ of sterile ringer solution (BR0052G, OXOID) and then pummelled in a Stomacher (BagMixer 400, Interscience) for $2 \mathrm{~min}$. Serial dilutions of the samples were analysed in solid media: total aerobic mesophilic bacteria in Plate Count Agar (Oxoid) incubated at $32{ }^{\circ} \mathrm{C}$ for $24 \mathrm{~h}$; lactic acid bacteria in De Man Rogosa and Sharpe Agar (Oxoid) added with $50 \mathrm{mg} \mathrm{l}^{-1}$ of Nystatin, incubated anaerobically at $32{ }^{\circ} \mathrm{C}$ for $48 \mathrm{~h}$; yeasts and moulds in Oxytetracycline Glucose Yeast Extract Agar (OGYE, Oxoid) at $25^{\circ} \mathrm{C}$ for $48 \mathrm{~h}$; Staphylococcus and Micrococcus spp. in Mannitol Salt Agar (Liofilchem) at $32{ }^{\circ} \mathrm{C}$ for $72 \mathrm{~h}$; Enterobacteriaceae on Violet Red Bile Glucose Agar (Oxoid) after $24 \mathrm{~h}$ at $37^{\circ} \mathrm{C}$. The analyses were done in triplicate, and the results were expressed as CFU g ${ }^{-1}$.

\subsection{Sensory analysis}

For the evaluation of the Quantitative Descriptive profile of the four product types, four different panels were formed each consisting of eight panellists (four females and four males, 22-34-year-old).

Samples were cut by means of a slicing electric machine to $2 \mathrm{~mm}$ thick slices for spicy sausage and $1.5 \mathrm{~mm}$ thick slices for soppressata and capocollo. 'Nduja samples, due to their particularly spreadable texture, were hand-cut and portioned in $50 \mathrm{~g}$ slices. All samples were left for $1 \mathrm{~h}$ at room temperature. All sessions were conducted at $22-25{ }^{\circ} \mathrm{C}$ in an eight booth sensory panel room equipped with white fluorescent lighting. During panel sessions, each sample was tasted in a randomized design with three replications. 
Sensory attributes were evaluated by using a continuous unstructured scale $(10 \mathrm{~cm})$ without references. The descriptors established for the products are shown in each score plot (Figs 2-5).

\subsection{Data analyses}

SPSS software (version 17.0, Inc.) was used for data processing. Two-way analysis of variance (Anova) was used to test the effect of the different companies and products on the final measured chemical and microbiological parameters. The data reported in the tables are means, standard deviation and significance. One-way Anova was used to test the effect of different cured meat products on mineral composition. Sensory analysis data were submitted to Principal Component Analysis.

\section{Results and discussion}

\subsection{Chemical analysis}

The composition analysis of the four Calabrian cured meat products is shown in Table 1. The physicochemical parameters were characterized by a wide variability: these findings are in line with the literature concerning other typical Italian fermented sausages (DELLAGLIO et al., 1996; Cenci-Goga et al., 2008; Zanardi et al., 2010).

Table 1. Influence of different companies and samples on the chemical composition of Calabrian cured meat products

\begin{tabular}{lcccccc}
\hline Samples & $\mathrm{a}_{\mathrm{W}}$ & $\mathrm{pH}$ & $\begin{array}{c}\text { Dry matter } \\
(\%)\end{array}$ & $\begin{array}{c}\text { Ash } \\
(\%)\end{array}$ & $\begin{array}{c}\text { Protein } \\
(\%)\end{array}$ & $\begin{array}{c}\text { Fat } \\
(\%)\end{array}$ \\
\hline CAP & $0.837 \pm 0.060$ & $6.02 \pm 0.39$ & $65.29 \pm 6.10$ & $4.75 \pm 0.88$ & $30.75 \pm 2.88$ & $25.57 \pm 3.18$ \\
ND & $0.804 \pm 0.074$ & $4.88 \pm 0.37$ & $75.04 \pm 7.45$ & $3.28 \pm 0.70$ & $24.80 \pm 2.56$ & $39.70 \pm 3.87$ \\
SAU & $0.805 \pm 0.063$ & $5.71 \pm 0.49$ & $69.87 \pm 4.72$ & $4.29 \pm 0.64$ & $29.83 \pm 2.25$ & $31.64 \pm 3.14$ \\
SOP & $0.835 \pm 0.059$ & $5.59 \pm 0.50$ & $64.48 \pm 4.75$ & $4.12 \pm 0.43$ & $29.26 \pm 1.13$ & $27.93 \pm 1.26$ \\
Significance & & & & & & $* *$ \\
Company & $* *$ & $*$ & $* *$ & $* *$ & $* *$ & $* *$ \\
Sample & $*$ & $* *$ & $* *$ & $* *$ & $* *$ & $*$ \\
Company $\times$ sample & $*$ & $*$ & n.s. & & $* *$ & $*$ \\
\hline
\end{tabular}

CAP: capocollo; ND: 'nduja; SAU: spicy sausage; SOP: soppressata. Data are shown as means and standard deviations. n.s.: not significant; $* \mathrm{P}<0.05 ; * * \mathrm{P}<0.01$

Regarding the chemical analyses reported in Table 1, the two-way Anova revealed that both company and different samples had an influence on the variability of the results, while the combined effect of company and sample did not affect the dry matter content.

The observed mean values of $a_{\mathrm{w}}$ in CAP, SAU and SOP were quite lower than those of other typical Italian products observed by other authors (DI CAGNO et al., 2008; ZANARDI et al., 2010). ND and SAU showed the lowest $\mathrm{a}_{\mathrm{w}}$ values among all samples, probably because of the particularly fatty pork cuts used for these typical products. The lowest water content 
was in line with the highest dry matter values of ND and SAU. The ND showed also the lowest $\mathrm{pH}$ value (4.88) probably due to the greater degree of grinding of the meat, pork fatty cuts and pepper sauce. Also, the ash and protein contents were the lowest compared to the other products.

The means of $\mathrm{a}_{\mathrm{w}}$, dry matter, protein and fat contents revealed a wide variability among the ten analysed companies (data not shown), showing that the influence of producer was always significant for all analyses.

\subsection{Mineral composition}

The mineral content of the different analysed products is shown in Table 2. As expected, sodium was the most representative mineral because of the salt addition necessary for hygienic and sensorial aspects. The second most abundant mineral was potassium, but there were no statistical differences for sodium and potassium elements among the samples. As for the other analysed minerals, the statistical analysis revealed a significance for magnesium $(\mathrm{P}<0.01)$ and for calcium $(\mathrm{P}<0.05)$.

Table 2. Mineral composition (mg/100 g) of Calabrian cured meat products

\begin{tabular}{lccccc}
\hline & CAP & ND & SAU & SOP & Significance \\
\hline $\mathrm{Na}$ & $2007 \pm 270$ & $2104 \pm 467$ & $1912 \pm 301$ & $2007 \pm 278$ & n.s. \\
$\mathrm{K}$ & $646 \pm 31.2$ & $570 \pm 116.9$ & $649 \pm 65.3$ & $626 \pm 56.0$ & n.s. \\
$\mathrm{Mg}$ & $18.94 \pm 3.55 \mathrm{c}$ & $20.91 \pm 5.42 \mathrm{bc}$ & $25.38 \pm 5.11 \mathrm{a}$ & $24.13 \pm 2.99 \mathrm{ab}$ & $* *$ \\
$\mathrm{Ca}$ & $7.52 \pm 2.02 \mathrm{~b}$ & $8.00 \pm 1.75 \mathrm{~b}$ & $8.51 \pm 2.20 \mathrm{ab}$ & $11.49 \pm 5.65 \mathrm{a}$ & $*$ \\
$\mathrm{Fe}$ & $4.64 \pm 0.80$ & $4.37 \pm 0.57$ & $4.24 \pm 0.77$ & $5.01 \pm 0.72$ & n.s. \\
$\mathrm{Zn}$ & $4.33 \pm 0.80$ & $4.52 \pm 0.84$ & $4.16 \pm 0.31$ & $4.88 \pm 0.69$ & n.s. \\
$\mathrm{Mn}$ & $0.30 \pm 0.11$ & $0.32 \pm 0.12$ & $0.34 \pm 0.08$ & $0.36 \pm 0.16$ & n.s. \\
\hline
\end{tabular}

CAP: capocollo; ND: 'nduja; SAU: spicy sausage; SOP: soppressata. Data are shown as means and standard deviations; n.s.: not significant; $* \mathrm{P}<0.05 ; * * \mathrm{P}<0.01$

The levels of most minerals are comparable to those detected by ZANARDI and co-workers (2010) in Italian salami. However, the means of $\mathrm{Na}, \mathrm{K}$ and Fe values, shown in Table 2, are higher than those reported by these authors (1881, 440 and $1.4 \mathrm{mg} / 100 \mathrm{~g}$, respectively), while the calcium level is strangely much lower (than $37 \mathrm{mg} / 100 \mathrm{~g}$ ), closer to the minimum value $(8 \mathrm{mg} / 100 \mathrm{~g})$. The level of $\mathrm{Mg}$ is comparable to the results previously reported by the authors $(16 \mathrm{mg} / 100 \mathrm{~g})$.

\subsection{Microbiological analysis}

Figure 1 shows the growth of different microbial population for all analysed Calabrian cured meat products. Different letters show significant difference for every single microbial population among the different products. 


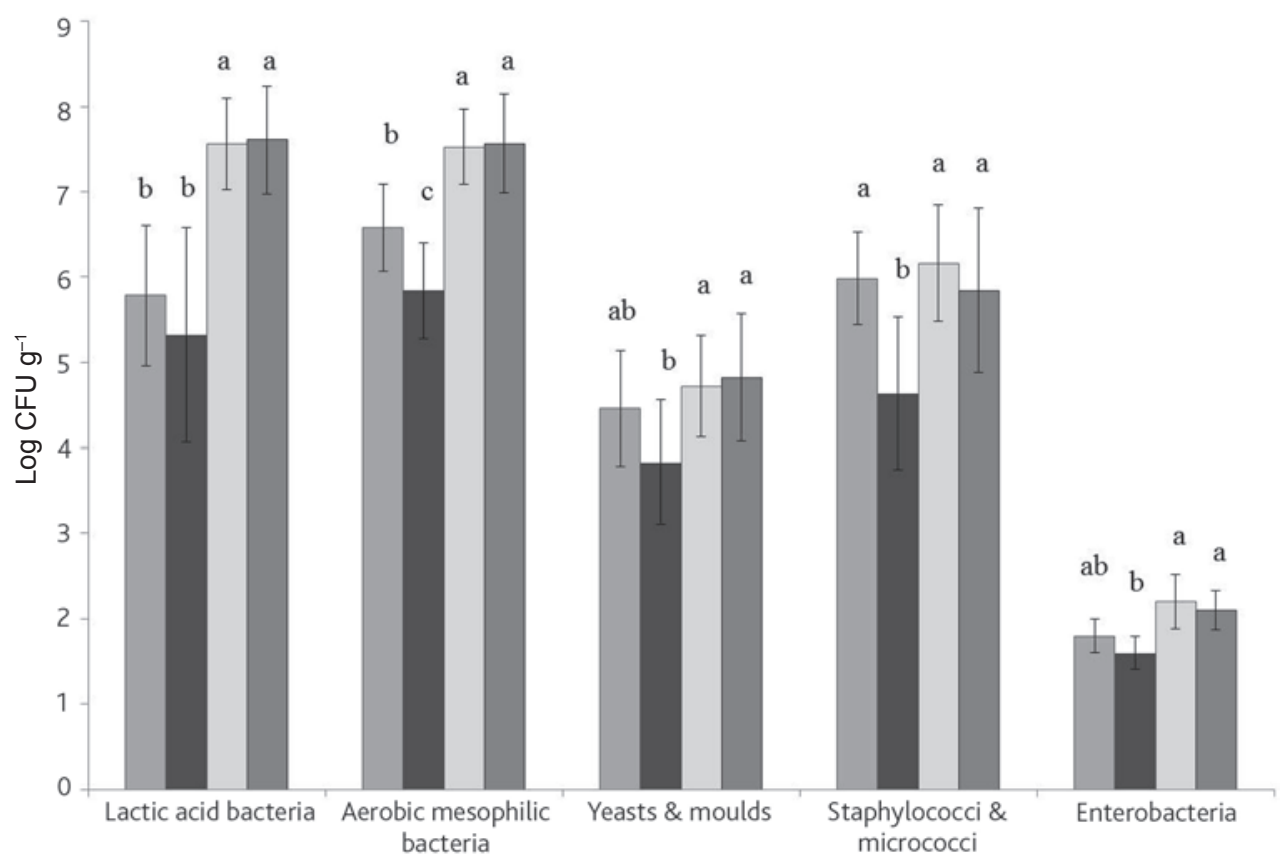

Fig. 1. Microbiological results of different Calabrian cured meat products. $\square$ : CAP; $\square:$ ND; $\square$ : SAU; $\square$ : SOP

The highest microbial level was reached by lactic acid bacteria (LAB) and total aerobic mesophilic bacteria on SAU and SOP samples, which were statistically similar for every tested microbial population. The lowest microbial counts were observed in ND samples, probably due to the antimicrobial effect of the added spices.

As expected, the initial homogenization of the meat caused greater distribution of microorganisms, which were at the highest level in SAU and SOP samples also after the ripening time, while in ND samples they were partially inhibited by the natural antimicrobial compounds present in spices. The levels of LAB, total aerobic mesophilic bacteria, yeasts and moulds, staphylococci and micrococci were quite similar to those reported by other authors (SAnz et al., 1997; Moretti et al., 2004; SAchindra et al., 2005; ViUdA-Martos et al., 2010). The Enterobacteriaceae exceeded $2 \log \mathrm{CFU} \mathrm{g}^{-1}$ in SAU and SOP samples, while other authors found a lower value at the end of maturation (SANZ et al., 1997; MoRETTI et al., 2004; KAMDEM et al., 2007). On the other hand, CoÏsson and co-workers (2004) in their study on Italian salamini found a slight increase of coliforms during processing up to $10^{4} \mathrm{CFU} \mathrm{g^{-1 }}$ after fermentation, without the influence of $\mathrm{pH}$ lowering. However, this value is under the limit imposed by Italian legislation for this kind of products (Reg. EC n. 2073/2005; KAMDEM et al., 2007).

The type of sample (CAP, ND, SAU and SOP) resulted significantly influential for all microbial populations, while the company only for yeasts and moulds (data not shown). 


\subsection{Sensory analysis}

Figure 2 shows the score plot of the Principal Component Analysis (PCA) related to the spicy sausage. The principal component, $\mathrm{PC} 1$, is positively related to the hardness, the overall flavour, and the orange tone, while it shows a negative correlation to the humidity. The second principal component, $\mathrm{PC} 2$, is principally linked to the spiciness of the samples.

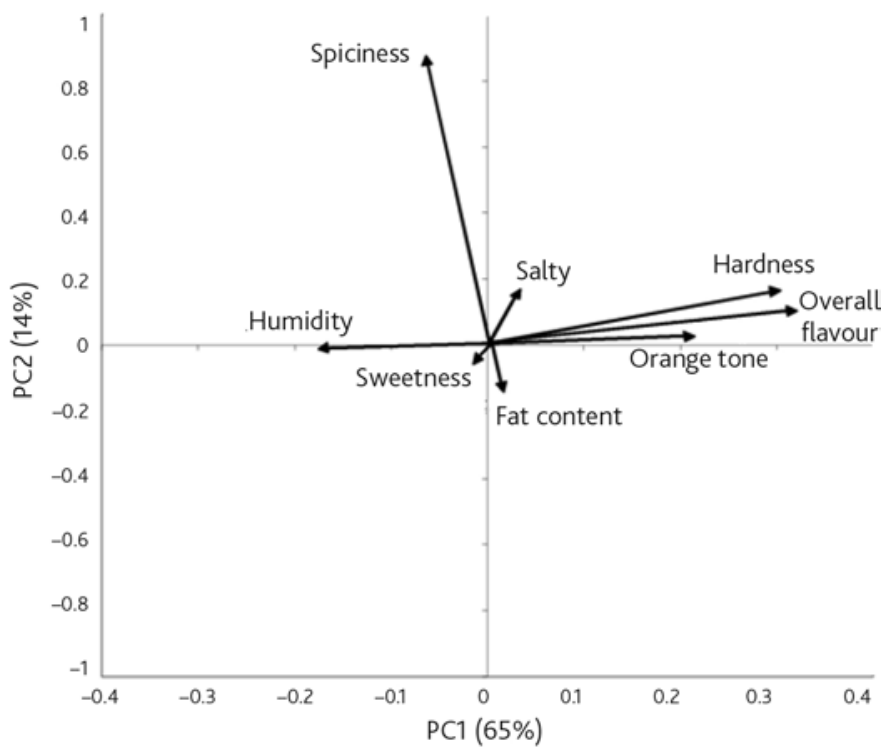

Fig. 2. Score plot of PCA showing separation of sensory variables along principal components PC1 and PC2 for spicy sausage

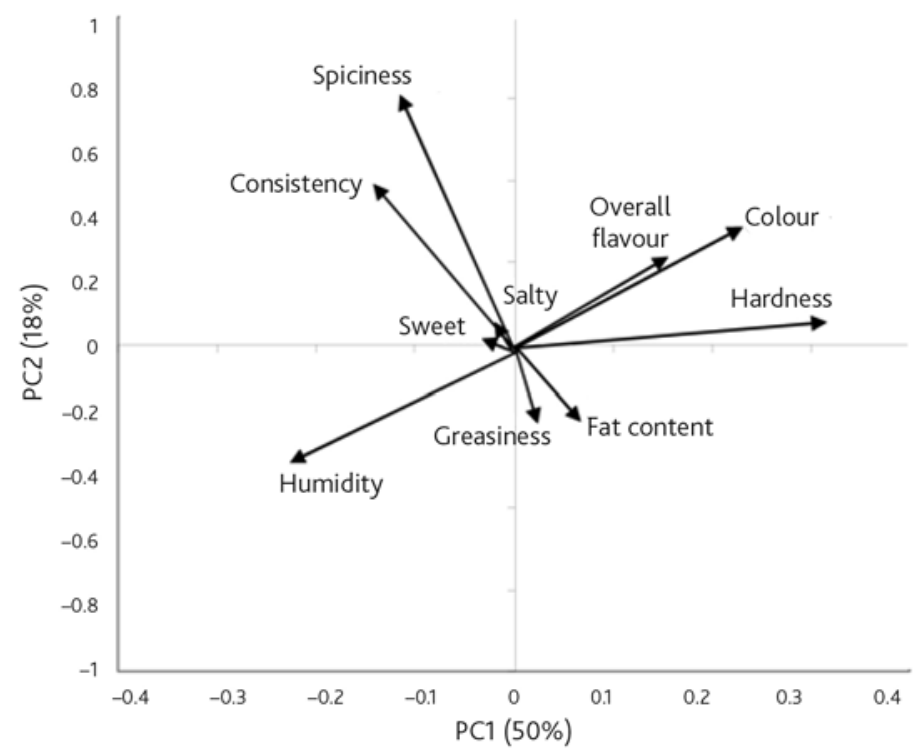

Fig. 3. Score plot of PCA showing separation of sensory variables along principal components PC1 and PC2 for soppressata 
Figure 3 shows the score plot of soppressata. The principal component, PC1, is positively correlated to the hardness, the colour intensity and the overall flavour, but negatively to the humidity (as in the case of sausage). The second principal component, PC2, is positively linked to the spiciness and consistency of the samples.

Figure 4 describes the results of PCA performed on 'nduja samples. The PC1 is positively correlated to the orange tone and spiciness, while the PC2 is related to the smoked, consistency, spreadability and greasy attributes. The 'nduja samples showed two main clusters (data not shown). The first cluster is characterized by the spreadability, greasiness and a low level of spicines with a consequent lower orange colour. The second cluster showed a major intensity in orange colour and spiciness. These products reflect the habit of some provinces to use a greater amount of red pepper.

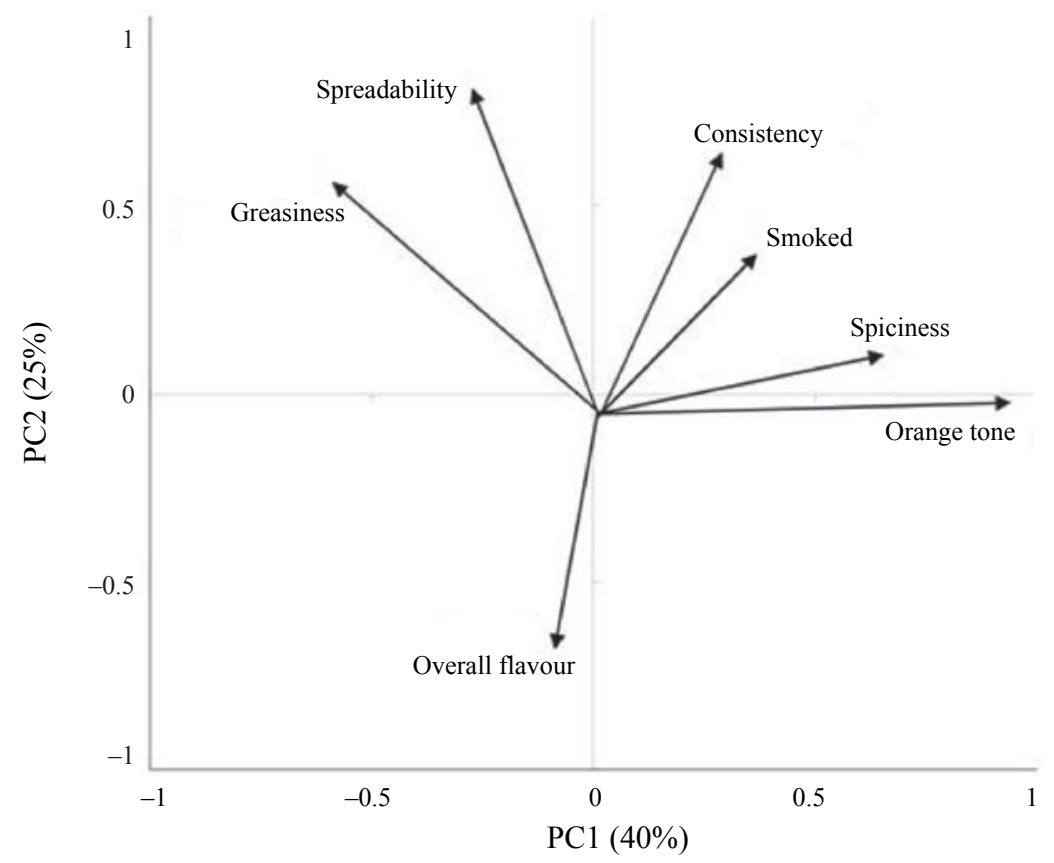

Fig. 4. Score plot of PCA showing separation of sensory variables along principal components PC1 and PC2 for 'nduja

Figure 5 shows the results of PCA performed on capocollo samples. The PC1 is positively correlated to overall flavour, hardness, saltiness, red tone and sliceability, while negatively to humidity. The PC2 is also positively related to spiciness, flavour and marbling, but negatively to sweet taste and colour uniformity. Concerning capocollo producer companies, the loading plot highlighted four clusters (data not shown). The variability of samples is caused by a higher number of attributes than the other types of products. 


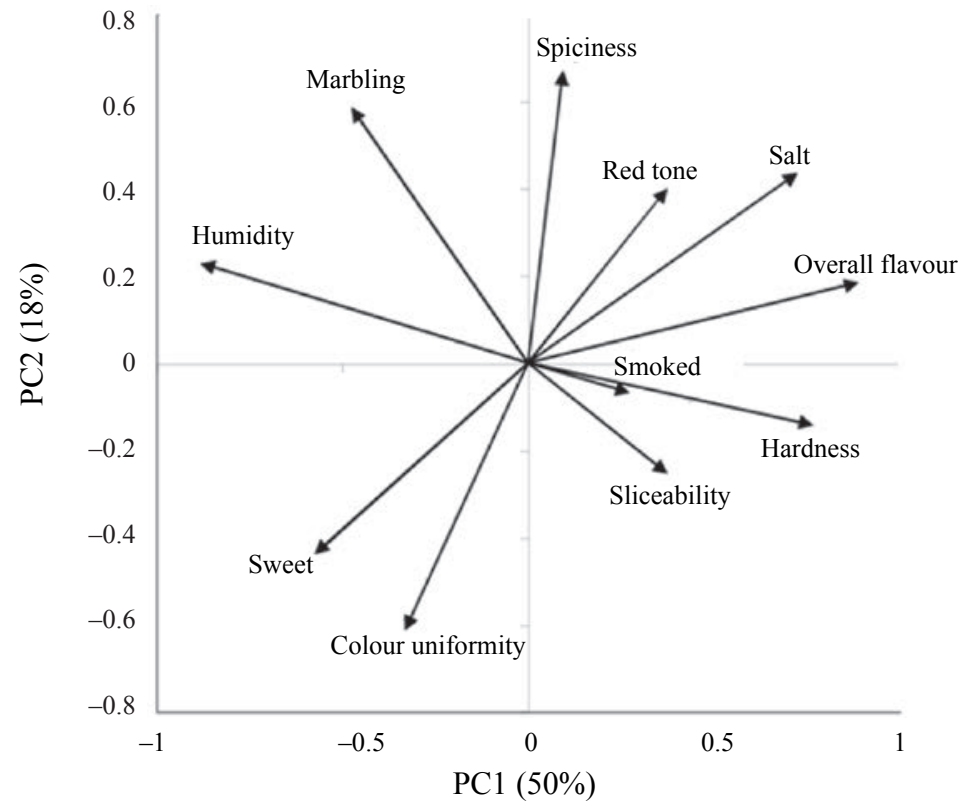

Fig. 5. Score plot of PCA showing separation of sensory variables along principal components PC1 and PC2 for capocollo

\section{Conclusions}

The analysed cured meat products presented many differences depending on the producer. Probably the habits related to the different provinces had also an influence.

The 'nduja samples showed the most chemical and microbiological differences among the analysed products, but this result was expected because of the different meat cuts and procedure used in relation to the other cured meat products.

The microbiological results were influenced both by company and product in a different way, depending on the considered microbial population.

According to the sensory analysis, all samples were acceptable. In particular, the samples of spicy sausage and soppressata showed the highest sensorial variability, while the "nduja samples were more easily clustered.

The results of this work drew attention to the high variability of typical food products of Southern Italy. In order to improve the level of quality, safety and standardization, the producers should adopt an uniform production method clearly defining product characteristics. Among technological options, the use of starters could help to obtain higher level of food safety and standardization.

\section{References}

A.O.A.C. (2000 a, b, c, d): Official methods of analysis. Association of Official Analytical Chemists, AOAC $17^{\text {th }}$ ed., Maryland, USA. a. Moisture in meat, No. 950.46; b. Ash. No. 920.153; c. Salt (Chlorine as sodium chloride) in meat. Volumetric method. No. 935.47; d. Nitrogen in meat, Kjeldahl method. No. 928.08. 
Cenci-Goga, B.T., Ranucci, D., Miraglia, D. \& Ciuffi, A. (2008): Use of starter cultures of dairy origin in the production of Salame nostrano, an Italian dry-cured sausage. Meat Sci., 78, 381-390.

Coïsson, J.D., Cerutti, C., Travaglia, F. \& Arlorio, M. (2004): Production of biogenic amines in "Salamini italiani alla cacciatora PDO". Meat Sci., 67, 343-349.

Dellaglio, S., Casiraghi, E. \& Pompei, C. (1996): Chemical, physical and sensory attributes for the characterization of an Italian dry-cured sausage. Meat Sci., 42, 25-35.

Di Cagno, R., Chaves lopez, C., Tofalo, R., Gallo, G., De Angelis, M., Paparella, A., Hammes, W.P. \& Gobetti, M. (2008): Comparison of the compositional, microbiological, biochemical and volatile profile characteristics of three Italian PDO fermented sausages. Meat Sci., 79, 224-235.

EC (1998): European Council Regulation, No. 134/98. Official Journal of European Community, January $20^{\text {th }} 1998$.

EC (2005): European Council Regulation, No. 2073/2005. Official Journal of European Community, November $15^{\text {th }}$ 2005.

EC (2006): European Council Regulation, No. 510/2006. Official Journal of European Community, March $20^{\text {th }}$ 2006.

Iaccarino, T., Di Monaco, R., Mincione, A., Cavella, S. \& Masi, P. (2006): Influence of information on origin and technology on the consumer response: The case of soppressata salami. Fd Qual. Prefer., 17, 76-84.

Kamdem, S.S., Patrignani, F. \& Guerzoni, M.E. (2007): Shelf-life and safety characteristics of Italian Toscana traditional fresh sausage (salsiccia) combining two commercial ready-to-use additives and spices. Fd Control, $18,421-429$.

Kupiec, B. \& Revell, B. (1998): Specialty and artisanal cheeses today: the product and the consumer. Brit. Fd J., 100, 236-243.

Moretti, V.M., Madonna, G., Diaferia, C., Mentasti, T., Paleari, M.A., Panseri, S., Pirone, G. \& Gandini, G. (2004): Chemical and microbiological parameters and sensory attributes of a typical Sicilian salami ripened in different conditions. Meat Sci., 66, 845-854.

Ockerman, H.W. \& Basu, L. (2007): Production and consumption of fermented meat products. -in: ToldrÁ, F. (Ed.) Handbook of fermented meat and poultry. Iowa, USA, Blackwell Publishing, pp. 9-15.

Ruusunen, M. \& Puolanne, E. (2005): Reducing sodium intake from meat products. Meat Sci., 70, 531-541.

Sachindra, N.M., SAKhare, P.Z., Yashoda, K.P. \& NARAsimha RaO, D. (2005): Microbial profile of buffalo sausage during processing and storage. Fd Control, 16, 31-35.

Sanz, Y., Vila, R., Toldrá, F., Nieto, P. \& Flores, J. (1997): Effect of nitrate and nitrite curing salts on microbial changes and sensory quality of rapid ripened sausages. Int. J. Fd Microbiol., 37, 225-229.

Talon, R., Leroy-Satrin, S. \& Fadda, S. (2004). Dry fermented sausages. -in: Hui, Y.H., Goddik, L.M., JosePhSEN, J., Stanfield, P.S., Hansen, A.S., Nip, W.K. \& ToldrÁ, F. (Eds) Handbook of food and beverage fermentation technology. Marcel Dekker Inc., New York, USA, pp. 397-416.

Viuda-Martos, M., Ruiz-Navajas, Y., Fernández-López, J. \& Pérez-Álvvarez, J.A. (2010): Effect of orange dietary fibre, oregano essential oil and packaging conditions on shelf-life of Bologna sausages. Fd Control, 21, 436443 .

Zanardi, E., Ghidini, S., Conter, M. \& IANIERI, A. (2010): Mineral composition of Italian salami and effect of NaCl partial replacement on compositional, physico-chemical and sensory parameters. Meat Sci., 86, 742-747. 